\title{
Quantifying the Operational Benefits of New HV Cable Systems in terms of Dielectric Design Parameters
}

\author{
J.A. Pilgrim*, P.L. Lewin and A.S. Vaughan \\ Tony Davies High Voltage Laboratory \\ University of Southampton \\ Southampton, UK \\ *jp2@ecs.soton.ac.uk
}

\begin{abstract}
In recent years, a significant volume of work has been undertaken on the development of novel dielectric materials which offer improvements in a variety of properties. Questions are frequently asked as to how particular properties can be improved by more intelligent dielectric design. However from the point of view of the network operator it is not just the dielectric design which is of interest - rather, how the finished product performs in the network. This paper seeks to demonstrate what quantifiable improvements in cable performance could be gained through advances in the dielectric properties of cable systems. The analysis is set in the context of the operational current rating of the cable circuit and the associated losses per unit of power transferred. Analysis of the results shows that the greatest improvement in cable operational performance can be made from increasing the dielectric thermal conductivity, even if it comes at the expense of a slight decrease in other properties.
\end{abstract}

Keywords-dielectric design; current rating; transmission cables;

\section{INTRODUCTION}

Over the past few decades, numerous researchers have investigated how improvements in dielectric design could lead to better performance from insulation systems in $\mathrm{HV}$ plant $[1,2]$. A wide array of solutions have been proposed which could lead to the availability of materials with higher breakdown strength, lower permittivity and loss angle, higher operating temperatures and greater thermal conductivity. However, from the point of view of cable systems, one of the key criteria is always "how much current can it carry?" The answer to this question is always a function of both the thermal and electrical properties of the cable itself and those of the environment in which the cable must operate. For network operators, to whom cost per unit of power transferred is critical, the current rating can be a major factor in deciding what cable to install.

\section{A. Measures of Operational Performance}

This paper seeks to demonstrate the impact of improvements in cable dielectric materials on operational performance through consideration of the impact on the current rating and losses per unit of power transferred in a benchmark $400 \mathrm{kV}$ cable system. It is recognized that these two factors are not the only measures of operational performance - factors such as asset life and the rate at which faults occur are also critical. For some utilities it is not presently necessary to account for network losses, hence the second consideration may not appear important - however, future regulation may seek to incentivize such operators to do so, thus it is still a factor worthy of consideration.

\section{DIELECTRIC PARAMETERS CONSIDERED}

A number of dielectric properties can be considered to have an effect on the operational performance of the cable system through contributing to the result of the cable rating calculation, or to the heat losses generated by the cable. Those considered within this paper are discussed in the following sections.

\section{A. Electrical Breakdown Strength}

The electrical breakdown strength $\left(E_{b}\right)$ of a cable dielectric will influence operational performance in a number of ways. Materials with higher $E_{b}$ are less likely to suffer failures due to transient voltage events while in service, although, for the purposes of this paper, the primary interest is the potential to reduce the thickness of the insulation itself. Most existing 400$\mathrm{kV}$ cables are designed such that the maximum electric stress under normal operation is in the range of $12-14 \mathrm{MV} / \mathrm{m}$. In practical terms, this typically leads to an insulation thickness of around $25 \mathrm{~mm}$ (excluding semiconducting screens).

Were the design stress of the cable to be increased due to improvements in the $E_{b}$ of the dielectric material, the required thickness of the insulation layer could be reduced. Two significant effects arise from this, firstly the possibility of a reduced thermal resistance between the conductor and cable surface. While this would clearly benefit the rating of the cable, the reduced dielectric thickness would also lead to the cable having a higher capacitance, $C_{d}(\mathrm{~F} / \mathrm{m})$, calculated by

$$
C_{d}=\frac{\epsilon}{18 \ln \left(\frac{D_{i}}{d_{c}}\right)} 10^{-9}
$$

where $\varepsilon$ is the relative permittivity of the dielectric material, $D_{i}$ is the external diameter of the dielectric (excluding screen), $\mathrm{mm}$ and $d_{c}$ is the diameter of the conductor (including screen), $\mathrm{mm}$. The increased capacitance will lead to both a higher dielectric loss, $W_{d}(\mathrm{~W} / \mathrm{m})$, 


$$
W_{d}=2 \pi f C_{d} U_{o}^{2} \tan \delta
$$

where $f$ is the frequency $(\mathrm{Hz}), U_{o}$ is the phase to earth voltage (V) and $\delta$ is the loss angle. It will also lead to a higher charging current, $\mathrm{I}_{\mathrm{c}}(\mathrm{A} / \mathrm{km})$,

$$
I_{c}=2 \pi f C_{d} U_{o}
$$

The higher the value of $I_{c}$, the shorter the maximum length of the cable circuit for which power can usefully be transferred [3]. Thus, although at first glance an increase in $E_{b}$ might appear wholly beneficial to the operational performance of a cable system through allowing a thinner dielectric, it can be seen that there are also trade-offs against other less desirable effects.

\section{B. Relative Permittivity}

The effects of dielectric relative permittivity have already been introduced in considering (1)-(3). It is clear that a lower relative permittivity would reduce the capacitance, hence giving a lower dielectric loss and charging current. Both of these effects are seen to be beneficial to our definition of operational performance.

\section{Loss Angle}

In an ideal dielectric the angle between the phase voltage and resultant current would be $90^{\circ}$, indicating that there was no component of current in phase with the applied voltage and hence no dielectric loss. For practical dielectrics, such a condition is not possible, with the typical value of $\delta$ in XLPE being around 0.05 degrees $(\tan \delta=0.001)$. From (2) it is apparent that reducing the value of $\delta$ will reduce the dielectric loss of the cable circuit. However, the significance of any such reduction may be small, given that the dielectric loss of modern XLPE cables is already as low as $2-3 \mathrm{~W} / \mathrm{m}$ per phase.

\section{Operating Temperature Limit}

For existing XLPE cable circuits, the standard continuous temperature limit (i.e. the temperature at which the cable can operate continuously without a reduction in its life) is $90^{\circ} \mathrm{C}$. In the majority of cases, it is this which limits the overall current rating of the cable circuit. Moving to a higher temperature limit could offer increased continuous and emergency ratings, as discussed in [4], but at the expense of higher losses per unit of power transferred, due to the temperature dependence of the ac resistance of the conductor. Significant increases in the operating temperature limit of XLPE are unlikely to be attainable, although investigations of other materials such as polypropylene suggest that values in excess of $120^{\circ} \mathrm{C}$ may eventually be achievable [5].

TABLE I. CABle Geometric Properties

\begin{tabular}{|l|l|l|l|}
\hline \multicolumn{1}{|c|}{ Component } & \multicolumn{1}{|c|}{ Material } & $\begin{array}{c}\text { Diameter } \\
(\mathbf{m m})\end{array}$ & \multicolumn{1}{|c|}{$\begin{array}{c}\text { Thermal Conductivity } \\
(\mathbf{W} / \mathbf{m . K})\end{array}$} \\
\hline Conductor & Copper & 65 & 385 \\
\hline $\begin{array}{l}\text { Conductor } \\
\text { Screen }\end{array}$ & $\begin{array}{l}\text { Semiconductive } \\
\text { polymer }\end{array}$ & 68 & 0.286 \\
\hline Dielectric & Polymeric & $68+2(t 1)$ & Varies \\
\hline $\begin{array}{l}\text { Dielectric } \\
\text { Screen }\end{array}$ & $\begin{array}{l}\text { Semiconductive } \\
\text { polymer }\end{array}$ & $71+2(t 1)$ & 0.286 \\
\hline Sheath & Aluminium & $75+2(t 1)$ & 250 \\
\hline Outer Sheath & Polyethylene & $88+2(t 1)$ & 0.286 \\
\hline
\end{tabular}

$t l=$ thickness of dielectric (not including screens)

\section{E. Thermal Conductivity}

The most significant contribution of the dielectric thermal conductivity to operational performance of the cable system is the influence it has on the conductor temperature. Increasing the thermal conductivity of the dielectric material reduces the thermal resistance between the main heat source at the conductor and the external environment. Thus, the conductor temperature for a given current would be lower (provided that all external factors remained constant), giving a higher current rating and also lower losses at a given load.

\section{STUDY OUTLINE}

The approach taken to quantifying the relative operational benefits of the different dielectric parameters is through considering the continuous cable rating and electrical losses in a common buried cable deployment scenario. This allows a sensitivity analysis to be undertaken to examine the effects of varying different parameters, or combinations thereof, on the cable circuit performance. This section of the paper outlines the methodologies and deployment scenarios considered.

\section{A. Cable Design}

The study presented here is based on a generic $400-\mathrm{kV}$ XLPE cable design in use on the UK transmission network. The 3-phase circuit is constructed from three single core cables with a $2500-\mathrm{mm}^{2}$ copper conductor of Milliken design using oxidized wires, covered by a thin semiconducting screen. The cable sheath is construction from aluminium, with a protective polyethylene oversheath. All sheaths are cross-bonded. Full geometric details are given in Table I, while Table II highlights the relevant electrical and thermal data for the circuit. It should be noted that in the diameters given in Table I, $t 1$ corresponds to the thickness of the dielectric (as this is one of the parameters varied during the investigation).

\section{B. Cable Rating Methodology}

A wide variety of techniques exist by which cable ratings can be calculated, ranging from simple analytical calculations to complex finite element studies. For the purposes of the analysis here, the only deployment scenario considered is for the cable to be directly buried at a depth of $1.5 \mathrm{~m}$ in a homogenous soil. Continuous ratings for this application can be easily and reliably calculated using the methodology of IEC 60287 [6]. This method represents the cable and its environment as a simple thermal resistance network which has

TABLE II. CABLE CIRCUIT THERMAL/ELECTRICAL CONSTANTS

\begin{tabular}{|l|l|l|}
\hline \multicolumn{1}{|c|}{ Parameter } & \multicolumn{1}{c|}{ Value } & \multicolumn{1}{c|}{ Units } \\
\hline Conductor Resistivity at $20^{\circ} \mathrm{C}$ & $1.72 \times 10^{-8}$ & $\Omega . \mathrm{m}$ \\
\hline $\begin{array}{l}\text { Conductor temperature coefficient of } \\
\text { resistivity }\end{array}$ & 0.00393 & $1 /{ }^{\circ} \mathrm{C}$ \\
\hline Skin effect coefficient & 0.45 & - \\
\hline Proximity effect coefficient & 0.2 & - \\
\hline Phase spacing (between core centres) & 750 & $\mathrm{~mm}$ \\
\hline Frequency & 50 & $\mathrm{~Hz}$ \\
\hline Phase Voltage & 230940 & $\mathrm{~V}$ \\
\hline Sheath Resistivity at $20^{\circ} \mathrm{C}$ & $2.84 \times 10^{-8}$ & $\Omega . \mathrm{m}$ \\
\hline Sheath temperature coefficient of resistivity & 0.00403 & $1 /{ }^{\circ} \mathrm{C}$ \\
\hline Burial Depth & 1.5 & $\mathrm{~m}$ \\
\hline Ambient temperature & 15 & ${ }^{\circ} \mathrm{C}$ \\
\hline Soil thermal resistivity & 1.2 & $\mathrm{~K} . \mathrm{m} / \mathrm{W}$ \\
\hline
\end{tabular}


been demonstrated to be sufficiently accurate against more complex models at this burial depth [7]. The only amendment made to the standard model is in the calculation of $T_{1}$ (thermal resistance between conductor and sheath), which is split into three parts to allow the thermal conductivity of the dielectric to differ from the surrounding semiconducting material.

\section{Method of Analysis}

In order to determine the sensitivity of the cable current rating and losses to the variation of design parameters, a 3 level 5 parameter orthogonal array technique (of the type presented in [8]) is used. The array used is a full factorial $3^{5}$ array, meaning that a total of 243 results are calculated ( 1 for each row of the matrix). The format of the array is,

$$
\left[\begin{array}{lllll}
1 & 1 & 1 & 1 & 1 \\
2 & 1 & 1 & 1 & 1 \\
3 & 1 & 1 & 1 & 1 \\
1 & 2 & 1 & 1 & 1 \\
2 & 2 & 1 & 1 & 1 \\
3 & 2 & 1 & 1 & 1 \\
1 & 3 & 1 & 1 & 1 \\
2 & 3 & 1 & 1 & 1 \\
3 & 3 & 1 & 1 & 1 \\
1 & 1 & 2 & 1 & 1 \\
2 & 1 & 2 & 1 & 1 \\
3 & 1 & 2 & 1 & 1 \\
\vdots & \vdots & \vdots & \vdots & \vdots
\end{array}\right]
$$

While the use of a full factorial approach is computationally expensive, in this case, the run time for each result is in the order of milliseconds and hence this approach proves viable. This is advantageous as the results for every single combination of the 5 factors, at all 3 levels, are calculated. This greatly eases the analysis of interactions between the variables, as it reduces the chance of confounding the interactions with the main effects.

Two results are gained for each experimental run, the first being the simple continuous rating (i.e. the value of current which led to the temperature of the hottest cable being equal to the stated maximum temperature). In Section I we stated that the second measure of operational performance to be investigated was the contribution of the cable circuit to the transmission network losses. The most appropriate way to represent these data is in the form of total circuit loss per circuit $\mathrm{m}$ per $\mathrm{kA}$, i.e. the sum of the Joule, dielectric and sheath losses for all three phases expressed in terms of $\mathrm{kA}$ transferred.

\section{Parametric Range Studied}

For each of the 5 parameters investigated, 3 levels were chosen to reflect possible future levels of improvement. It should be stressed that no consideration is given here to how these improvements might be achieved - we are interested solely on the effects which would result from them. The levels themselves are not hugely important, given that we are interested mainly in the normalized response. Table III shows

TABLE III. PARAMETER RANGES STUDIED

\begin{tabular}{|c|c|c|c|}
\hline Parameter & Level 1 & Level 2 & Level 3 \\
\hline $\begin{array}{l}\text { [A] Dielectric Thickness } \\
(t 1)\end{array}$ & $25 \mathrm{~mm}$ & $22.5 \mathrm{~mm}$ & $20 \mathrm{~mm}$ \\
\hline [B] Relative Permittivity & 2.5 & 2.25 & 2.0 \\
\hline$[C] \operatorname{Tan} \delta$ & 0.001 & 0.0005 & 0.0001 \\
\hline [D] Temperature Limit & $90^{\circ} \mathrm{C}$ & $100^{\circ} \mathrm{C}$ & $110^{\circ} \mathrm{C}$ \\
\hline $\begin{array}{l}{[\mathrm{E}] \text { Dielectric Thermal }} \\
\text { Conductivity }\end{array}$ & $0.286 \mathrm{~W} / \mathrm{m} . \mathrm{K}$ & $0.5 \mathrm{~W} / \mathrm{m} . \mathrm{K}$ & $0.714 \mathrm{~W} / \mathrm{m} . \mathrm{K}$ \\
\hline
\end{tabular}

the input ranges used. Level 1 corresponds broadly to the reference design of the existing $400 \mathrm{kV}$ XLPE circuit, while levels 2 and 3 represent increments in material performance.

\section{FACTORIAL SENSITIVITY ANALYSIS}

This section documents the results obtained from undertaking the factorial sensitivity analysis, identifying the key drivers which would boost cable performance.

\section{A. Summary of Main Effects}

The main effects of a parameter can be considered in a straightforward way simply by comparing the average results obtained when that factor was at different levels. Full factorial experiments are said to be 'balanced', meaning for instance that for all tests where $A$ is at $\mathrm{L} 1$, all other factors are tested an equal number of times at each of their levels. Tables IV and V illustrate the response table for both current rating and losses across the full range of experiments.

\section{1) Linear Effects}

The simplest way to consider the response of the result, $y$, is to determine the slope of the straight line between the responses at L1 and L3 of any given parameter (the linear effect of $A$ on $y$, for example). These values are termed as the linear contrasts. They are obtained mathematically by recoding the array to have levels of $-1,0$ and +1 (corresponding to the 1 , 2 and 3 of (4)) and then performing the following operation on each column:

$$
\alpha_{l}=\frac{\sum_{n=1}^{N} c l_{n} R_{n}}{2 N / 3}
$$

where $\alpha_{l}$ is the linear effect, $N$ is the number of runs, $c l_{n}$ is the entry in the linear contrast coefficient vector at row $n$ and $R$ is the result vector.

\section{2) Quadratic Effects}

Clearly in many cases (particularly this one where the results contain functions of $I^{2} R$ ), assuming a straight line between points would lead to errors. Thus quadratic contrasts $\alpha_{q}$ are introduced which give a measure of the extent to which two points are not collinear - i.e. the distance of response L2 from the straight line between L1 and L3, allowing a quadratic relationship between a factor and the resulting response to be calculated. The quadratic contrast is calculated as per (5) except that $c l$ is replaced by $c q$, the vector of quadratic contrasts. This vector is again based on the array of (4) but with 1,2 and 3 becoming $+1,-2$ and +1 respectively. As the linear and quadratic contrasts typically vary in magnitude, it can be valuable to standardize them by dividing the contrast by $k$, defined as

$$
k=\sqrt{\frac{\sum c c^{2}}{d^{2}}}
$$

where $c c$ is the coefficient in the contrast column and $d$ is the divisor, found by summing the absolute value of the $1 \mathrm{~s}$ in the contrast column. The value of this operation can be seen when considering the half normal probability plots to determine the most significant factors and interactions between factors. 
TABLE IV. RESPONSE TABLE (CONTINUOUS CURRENT RATING)

\begin{tabular}{|l|c|c|c|c|c|}
\hline & A & B & C & D & E \\
\hline Response at L1 & $2188 \mathrm{~A}$ & $2187 \mathrm{~A}$ & $2154 \mathrm{~A}$ & $2078 \mathrm{~A}$ & $2125 \mathrm{~A}$ \\
\hline Response at L2 & $2192 \mathrm{~A}$ & $2191 \mathrm{~A}$ & $2194 \mathrm{~A}$ & $2195 \mathrm{~A}$ & $2207 \mathrm{~A}$ \\
\hline Response at L3 & $2194 \mathrm{~A}$ & $2196 \mathrm{~A}$ & $2226 \mathrm{~A}$ & $2301 \mathrm{~A}$ & $2242 \mathrm{~A}$ \\
\hline Linear Effect on Rating & 3.01 & 4.81 & 36.2 & 111.2 & 58.8 \\
\hline $\begin{array}{l}\text { Quadratic Effect on } \\
\text { Rating }\end{array}$ & -0.35 & 0.04 & -4.3 & -5.3 & -23.2 \\
\hline $\begin{array}{l}\text { Standardised Linear } \\
\text { Effect }\end{array}$ & 38.3 & 61.3 & 461 & 1416 & 748 \\
\hline $\begin{array}{l}\text { Standardised Quadratic } \\
\text { Effect }\end{array}$ & -2.59 & 0.27 & -31.8 & -38.6 & -170 \\
\hline
\end{tabular}

TABLE V. RESPONSE TABLE (LOSSES PER CIRCUIT METRE PER KA)

\begin{tabular}{|l|c|c|c|c|c|}
\hline & A & B & C & D & E \\
\hline Response at L1 & $74.7 \mathrm{~W}$ & $75.1 \mathrm{~W}$ & $76.4 \mathrm{~W}$ & $69.8 \mathrm{~W}$ & $72.8 \mathrm{~W}$ \\
\hline Response at L2 & $74.9 \mathrm{~W}$ & $74.9 \mathrm{~W}$ & $74.7 \mathrm{~W}$ & $74.9 \mathrm{~W}$ & $75.4 \mathrm{~W}$ \\
\hline Response at L3 & $75.1 \mathrm{~W}$ & $74.7 \mathrm{~W}$ & $73.5 \mathrm{~W}$ & $79.9 \mathrm{~W}$ & $76.5 \mathrm{~W}$ \\
\hline Linear Effect on Losses & 0.18 & -0.19 & -1.24 & 4.94 & 1.11 \\
\hline $\begin{array}{l}\text { Quadratic Effect on } \\
\text { Losses }\end{array}$ & 0.02 & $-6 \times 10^{-4}$ & 0.19 & -0.07 & -0.72 \\
\hline $\begin{array}{l}\text { Standardised Linear } \\
\text { Effect }\end{array}$ & 2.36 & -2.46 & -18.2 & 63.8 & 23.3 \\
\hline $\begin{array}{l}\text { Standardised Quadratic } \\
\text { Effect }\end{array}$ & 0.15 & -0.004 & 1.42 & -0.54 & -5.32 \\
\hline
\end{tabular}

\section{3) Interpretation of Main Effects}

Considering the results in both Table IV and V, a number of trends stand out from the standardised main effects. For both the current rating and loss per $\mathrm{kA}$ per $\mathrm{km}$, the largest linear effect comes from factor $D$ (temperature limit), followed by $E$ (thermal conductivity). These parameters also show the largest quadratic effects. Interestingly parameter $A$ (dielectric thickness) is shown to have a relatively small effect on the results across the range studied. This can be attributed to the fact that the reduction in thermal resistance achieved by thinning the dielectric is offset by the resulting increase in dielectric losses. The gains from further reducing the cable capacitance (through a reduction in factor $B$ relative permittivity) are also small.

It should be noted that for the data in Table V, a positive linear effect represents an increase in losses per unit of power transferred and hence a decrease in operational efficiency. It is therefore unsurprising that a large positive effect is seen for $D$ (temperature limit), as the ac resistance (and hence current dependent losses) will increase with temperature. What is more surprising is that the linear effect for an increase in dielectric thermal conductivity is also positive. This suggests an interaction with another factor in the experiment.

\section{B. Interaction Analysis}

As noted in the analysis of the main effects, some interactions appear to be evident within the data. Interactions can be considered as, for example, the linear effect of $\mathrm{A}$ on the linear effect of $B\left(A_{l} X B_{l}\right)$. They are calculated using the same procedure as the main effects, except that there will be two ' $c$ ' terms multiplied together in the summation of (5). For example, to determine the linear by linear interaction of $A$ and $B$ the relevant terms would be $c_{l(A) n}$ and $c_{l(B) n}$. The most significant interactions can be easily identified using a half

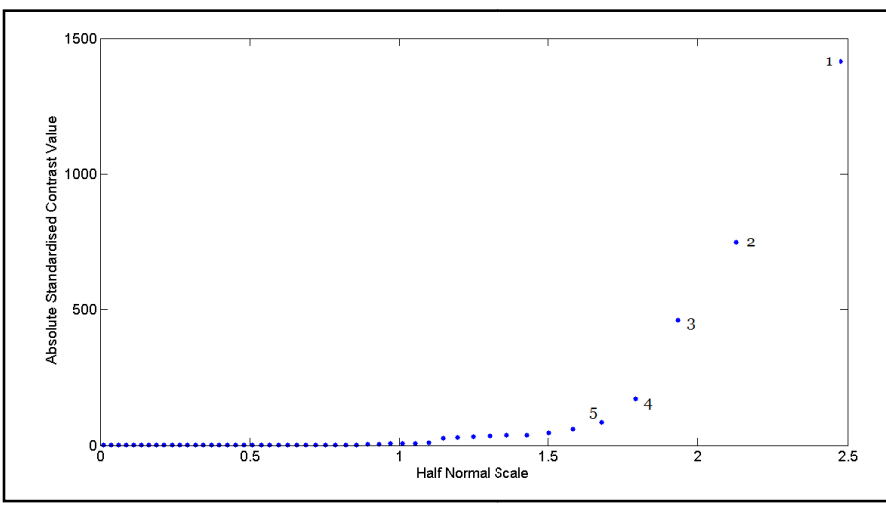

Figure 1. Half normal plot for main effects and interactions of current rating. $1=D_{l}, 2=E_{l}, 3=C_{l}, 4=E_{q}, 5=B_{l} X C_{l}$

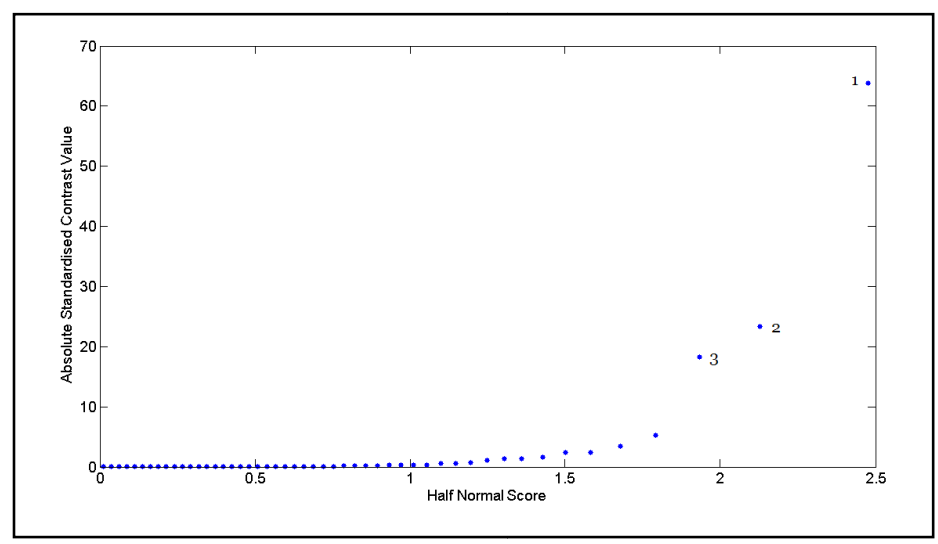

Figure 2. Half normal plot for main effects and contributions to network losses. $1=D_{l}, 2=E_{l}, 3=C_{l}$

normal plot, where the absolute values of the standardized contrasts are plotted against half normal scores. Fig. 1 shows the results for the current rating results, while Fig. 2 shows those for the contribution to network losses. Only first order interactions are considered - analysis of the second order interactions shows negligible standardized values. In both plots, the most significant effects and interactions are numbered. The results of Fig. 2 are easily interpreted as the most significant contrasts for losses all relate to the main effects, with interactions being negligible. As noted in Section IV $C$, the conductor temperature limit has the greatest impact on the losses per kA transferred, followed by dielectric thermal conductivity and $\tan \delta$. The most significant interaction is $B_{l} X C_{l}$, but this is an order of magnitude smaller than the impact of the conductor temperature.

Analysis of Fig. 1 is more complex. Of the 5 most important effects, the largest 3 are the main linear effects of temperature limit, thermal conductivity and $\tan \delta$. The fourth most significant is $E_{q}$, the quadratic effect of dielectric thermal conductivity. This emphasizes the non-linear relationship between dielectric thermal conductivity and current rating. Such a relationship arises because the heat output of the cable under load is broadly quadratic (dependent on $I^{2}$ ), thus a small increase in thermal conductivity gives a larger per unit increase in current rating than a larger increase. This will be investigated further in the next section of the paper. 


\section{TRADE-OFFS}

Through conducting the factorial sensitivity analysis of Section IV, it has been demonstrated that of the 5 dielectric properties considered the most significant improvements in operational performance can be obtained from better dielectric thermal conductivity. While increasing the operating temperature can deliver a higher rating, it comes at the expense of higher losses per unit of power transferred. Improving the thermal conductivity of a polyethylene dielectric has been found to be possible through a variety of means, for instance addition of boron nitride [9] or by amending the chain structure [10]. However, in some cases acting to improve one property risks worsening another. The results of the sensitivity analysis suggest that in some instances this may be tolerable.

As an example, we consider the possibility that an improvement can be made to the thermal conductivity but at the expense of a slight decrease in breakdown strength, necessitating an increase in dielectric thickness. Fig. 3 shows results for the continuous current rating with varying dielectric thermal conductivity and several dielectric thicknesses. Unless otherwise specified, all of the curves in Fig. 3 represent parameters other than thermal conductivity being at their L1 level from Table III. Examination of the curves complements the output of the sensitivity analysis, illustrating that the dielectric thickness itself has very little impact on the rating in this case, while the impact of increasing the relative permittivity to 2.8 from 2.5 is also small. Meanwhile an increase in $\tan \delta$ from 0.001 to 0.0015 can be seen to have greatly decreased the rating when compared to the base data.

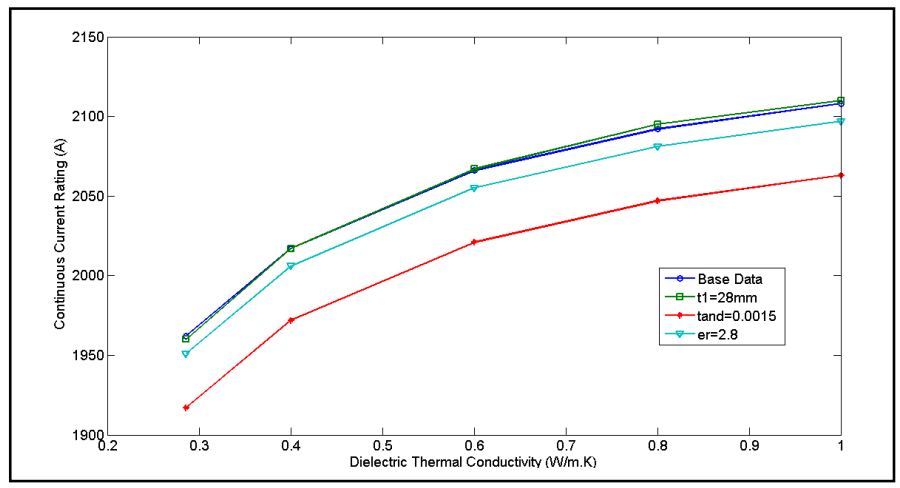

Figure 3. Effect of Thermal Conductivity on Rating with various trade offs

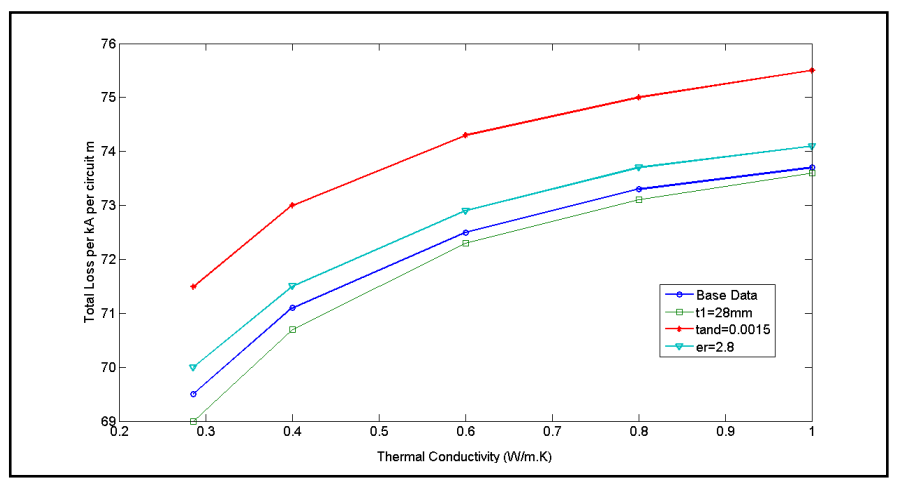

Figure 4. Effect of Thermal Conductivity on Losses with various trade offs
However, if this was the only consequence of moving from a thermal conductivity of $0.286 \mathrm{~W} / \mathrm{m} . \mathrm{K}$ (that of XLPE) to 1 $\mathrm{W} / \mathrm{m} . \mathrm{K}$, a gain of $100 \mathrm{~A}$ is still realized. Thus the increment in dielectric loss, whose effect can clearly be seen from the red curve of Fig. 4, may prove to be acceptable to a utility.

\section{CONCLUSIONS}

This paper has sought to consider quantitatively the benefits in improving various dielectric properties from the point of view of a $400-\mathrm{kV}$ cable system. Through the use of a full factorial experiment, the sensitivity of both cable continuous rating and energy loss per unit of power transferred to various dielectric properties was calculated. The results obtained demonstrate that the properties offer the greatest per unit improvement in rating were temperature limit and thermal conductivity, although the former also leads to a reduction in the efficiency of power transfer due to higher resistive losses. The sensitivity to dielectric thickness and relative permittivity were demonstrated to be low. This fact is key as it demonstrates that cable performance could be improved through improving the dielectric thermal conductivity, even if this comes at the expense of a slight worsening in other areas. The crux of the problem is the development of materials which generate the desired increase in thermal conductivity, but without incurring excessively adverse effect on $\tan \delta$ or diminishing the life expectancy of the cable in service.

\section{REFERENCES}

[1] I. L. Hosier, A. S. Vaughan and S. G. Swingler, "Structure-property relationships in polyethylene blends: the effect of morphology on electrical breakdown strength," Journal of Materials Science, vol. 32, no. 17, pp4523-4531. 1997.

[2] R. Kochetov, A. V. Korobko, T. Andritsch, P. H. F. Morshuis, S. J. Picken and J. J. Smit, "Modelling of the thermal conductivity in polymer nanocomposites and the impact of the interface between filler and matrix," Journal of Physics D: Applied Physics, vol. 44, no. 39, 395401. 2011

[3] G. Moore (Ed), Electric Cables Handbook, Third Edition. Blackwell Science, Oxford, UK, 1997.

[4] J. A. Pilgrim, D. J. Swaffield, P. L. Lewin, S. G. Swingler, F. Waite and D. Payne, "Impact of moisture migration on the current rating of high operating temperature power cables," Proceedings of $8^{\text {th }}$ International Conference on Insulated Power Cables (Jicable), June 2011, Versailles, France, pp222-227.

[5] I. L. Hosier, A. S. Vaughan and S. G. Swingler, "An investigation of the potential of polypropylene and its blends for use in recyclable high voltage cable insulation systems," Journal of Materials Science, vol. 46, no. 11, pp. 4058-4070, June 2011.

[6] International Electrotechnical Commission, "Electric Cables Calculation of the current rating BS IEC $60287-1-1: 2006$ " British Standards Institution.

[7] D. J. Swaffield, P. L. Lewin and S. J. Sutton, "Methods for rating directly buried high voltage cable circuits," IET Generation, Transmission and Distribution, vol. 2, no.3, pp393-401, 2008.

[8] D. M. Grove and T. P. Davis, Engineering, Quality and Experimental Design. London, UK. Longman, 1992.

[9] W. Zhou, S. Qi, H. Li and S. Shao, "Study on insulating thermally conductive BN/HDPE nanocomposites," Thermochimica Acta, vol. 452, pp36-42. 2007.

[10] S. Shen, A. Henry, J. Tong, R. Zhen and G. Chen, "Polyethylene nanofibres with very high thermal conductivity," Nature Nanotechnology, vol. 5, pp $251-255.2010$. 